\title{
ЭКОНОМИКО-ПРАВОВЫЕ АСПЕКТЫ КЛАССИФИКАЦИИ РИЭЛТОРСКИХ УСЛУГ С УЧЕТОМ ЦИФРОВИЗАЦИИ ОБОРОТА НЕДВИЖИМОСТИ
}

\author{
(c) 2020 Шпанагель Федор Федорович
}

кандидат юридических наук, доцент кафедры правового обеспечения экономических отношений Самарский государственный экономический университет, Россия, Самара

E-mail: shpanur@yandex.ru

В статье рассмотрено воздействие цифровизации экономики на рынок риэлторских услуг в условиях кризиса; проведена классификация услуг, оказываемых риэлторскими организациями; показана условность и неполнота деления услуг на фактические и юридические. Автором выделена группа информационных услуг с учетом их возрастающей роли в функционировании рынка недвижимого имущества.

Ключевые слова: цифровые технологии, риэлторские организации, классификация услуг, информацзионные услуги, посреднические услуги, юридические услуги.

Происходящие в экономике изменения существенно ускорились в связи с использованием многочисленных и разнообразных информационных технологий во всех сферах жизни общества. Данные изменения отразились и на функционировании рынка недвижимости.

В настоящее время в мировой экономике возникла уникальная ситуация взаимодействия различных и мощных по силе факторов негативного характера, умножающих степень неопределенности как в масштабах глобальных и региональных рынков, так и (в еще большей мере) в деятельности предпринимателей.

Кризис на рынке углеводородов в сочетании с пандемией вируса COVID-19 ускорили уже начавшийся массовый переход стран от глобализации к протекционизму, что обусловливает использование всеми государствами различных средств обеспечения финансовой и в целом экономической безопасности, мероприятий по усилению инвестиционной привлекательности национальной правовой и экономической среды бизнеса, защиты своих национальных рынков, и другие.

Перечисленные выше и другие обстоятельства в разнообразном взаимодействии способны вызвать или по крайней мере ускорить изменения круга объектов недвижимого имущества, объем его оборота, существенно изменив (чаще всего кардинально снизив) ликвидность большинства объектов (квартир и жилых домов большой площади как вторичного, так и в еще большей степени первичного рынка жилья, офисных помещений и других), и обусловив появле- ние новых объектов. Так, в последнее десятилетие усилились тенденции разумной экономии и совместного потребления недвижимости, вызвавшие появление недвижимости с функцией, например, коворкингов (коллективных офисов), коливингов (домов совместного проживания) и других.

Новые объекты недвижимого имущества, в том числе вышеперечисленные, появились в экономически развитых странах значительно раньше, по крайней мере до начала пандемии и даже не в связи с экономическим кризисом, возникшим в 2020 году.

Закономерности и события, названные выше, оказывают заметное влияние на сферу услуг на рынке недвижимого имущества, причем наиболее существенное - на риэлторскую деятельность, включая резкое сокращение количества сделок и изменение перечня оказываемых риэлторскими организациями услуг.

В процессе усиливающейся конкуренции на рынке услуг в сфере недвижимости значительные преимущества приобретают риэлторские организации, последовательно осваивающие новые информационные технологии, которые позволяют улучшить сотрудничество и стратегическое управление объектами недвижимости, например, системы геоинформационных услуг через приложение Geomanagement, которое поддерживает реализацию стратегии брокерского агентства недвижимости, основанной на мобильности и совместной работе его сотрудников, в том числе территориально разобщенных.

Исследование риэлторской деятельности 
позволяет обнаружить тенденцию возрастания роли информационных услуг, оказываемых в процессе ее осуществления, на которые исследователи ранее не обращали особого внимания.

Практика предоставления услуг, том числе на рынке недвижимого имущества, позволяет сделать более широкое обобщение: названная нами тенденция характерна для всей сферы услуг, включая государственные и муниципальные услуги.

Анализ изменений в деятельности риэлторских организаций и в целом на рынке недвижимости, вызванных внедрением и использованием цифровых технологий, позволяет условно разделить риэлторские услуги на:

1) цифровые и непосредственно (и неразрывно) связанные с ними услуги риэлторских организаций;

2) остальные (нецифровые) услуги, оказываемые риэлторскими организациями, например, при определении и уточнении характеристики объектов недвижимости (их локации, цены и других индивидуальных запросов заказчиков), а также в процессе сопровождения и (или) представительства клиентов на переговоpax с потенциальными покупателями, продавцами, арендодателями, арендаторами и другими участниками рынка недвижимости. Правда, степень и охват достигнутой к настоящему времени цифровизации всех сторон жизни современного российского общества почти полностью исключают предоставление риэлторами услуг без использования возможностей цифровых технологий.

Хронология перехода риэлторских организаций, передовых в данной отрасли, к использованию информационных технологий, позволяет изучить темпы и широту их использования, сравнить со скоростью и глубиной проникновения цифровых технологий в деятельность передовых участников рынка недвижимости в зарубежных странах, учесть и использовать ценный опыт, по возможности перенять наилучшие практики.

Использование информационных технологий позволяет риэлторским организациям существенно расширить разнообразие предоставляемых ими услуг и их содержание, скорость их предоставления, существенно снизить правовые и иные риски при совершении сделок с объектами недвижимого имущества, создать наиболее удобные условия для клиентов.
Представляется неточным использование в качестве равнозначных терминов «информационные услуги» и «цифровые услуги», поскольку значительная, причем конфиденциальная и коммерческая информация может передаваться без использования цифровых технологий и, наоборот, цифровые технологии все в большей степени «пронизывают» не только информационные, но и все другие виды риэлторских услуг.

При анализе информационных услуг представляется интересным мнение Е.Г.Шабловой о блочных элементах информации, которую обязан довести до каждого заказчика исполнитель по договору возмездного оказания услуг.

Данное правило полностью применимо и к сфере оказания риэлторских услуг.

В связи с этим считаем необходимым ввести так называемую информационную обязанность исполнителя не только применительно к обязательствам по возмездному оказанию услуг, регулируемых нормами главы 39 кодифицированного акта российского гражданского законодательства, но в качестве общего требования при исполнении договорных обязательств путем дополнения статьи 308.3 Гражданского кодекса РФ дополнительным пунктом 1 следующего содержания:

«1. В процессе исполнения обязательства каждая сторона обязана сообщить другой стороне всю необходимую информацию для исполнения обязательства или для принятия исполнения.»

При заключении договора на оказание риэлторских услуг в сведениях, сообщаемых заказчику, должна содержаться:

1) информация о самом исполнителе, различающаяся в зависимости от личности риэлтора: коммерческой организации или индивидуального предпринимателя;

2) информация, причем достаточно подробная, которая характеризует саму риэлторскую услугу или набор услуг, исключающая признание договора недействительным из-за неопределенности его предмета;

3) информация, раскрывающая обоснование цены каждой услуги и цены договора в целом, если исполнитель принял на себя обязанность оказания заказчику больше одной услуги (достаточная и соответствующая требованиям налогового учета).

В пределах выше перечисленных блоков информации необходимо закрепить в законодательном или другом нормативно-правовом акте 
о риэлторской деятельности сведения, которые можно, в свою очередь, разделить на императивные и факультативные элементы информации.

Практически отсутствуют, за исключением определенных правовыми актами персональных данных, ограничения гражданским законодательством объема и видов информации, которую риэлтор в договоре может обязаться предоставить заказчику: о контрагентах, объектах недвижимого имущества, условиях предоставления риэлторских услуг и другую.

Такие сведения можно назвать факультативными элементами информационного блока данных, круг которых является строго индивидуальным для каждого договора на оказание риэлторских услуг и определяется запросами (информационными потребностями) конкретного заказчика.

Наиболее важная информация для обеспечения интересов всех или большинства заказчиков и необходимая для осуществления и защиты ими своих прав должна быть по ее объему и видам императивно закреплена законодательством.

В научных публикациях о риэлторской деятельности нередко ограничивают предмет так называемого риэлторского договора или договора на оказание риэлторских услуг исключительно услугами фактического характера.

В целом критически оценивая такую позицию авторов, к тому же не подтвержденную необходимыми аргументами, считаем возможным, используя ее, провести классификацию риэлторских услуг на фактические, юридические и объединенные на основании такого критерия как характер деятельности риэлтора в процессе реализации той или иной услуги.

1. К услугам фактического характера отнесем основные услуги риэлтора из выше рассмотренного деления риэлторских услуг на основные и дополнительные или факультативные.

К услугам фактического характера следует отнести только такие действия или деятельность риэлтора, которые направлены на формирование воли участников на совершение сделки, но не на изъявление их воли.

В эту группу услуг можно включить, в частности, деятельность риэлтора, направленную на организацию и проведение согласования условий предстоящей сделки. К таким услугам следует отнести только такие действия или де- ятельность риэлтора, которые он совершает в процессе осуществления им посреднических функций.

Действия этого вида направлены на поиск необходимого числа конкретных потенциальных контрагентов (двух или нескольких), организацию их взаимодействия (переговоров) и на подготовку сделки или сделок между ними.

В эту же группу фактических действий можно включить направление запросов в соответствующие государственные и иные органы управления об объекте или объектах недвижимого имущества на наличие возможных ограничений и обременений; об их законных собственниках/ владельцах (совместно с ними о состоянии их здоровья, прежде всего психического), и многие другие.

2. К услугам юридического характера следует отнести только такие действия или деятельность риэлтора, которые направлены на изъявление воли участников сделки, а также на надлежащее оформление их совместного волеизъявления.

В качестве примера таких действий нередко называют договоры поручения и комиссии, что вызывает определенные возражения.

Для уточнения характера действий самого риэлтора, а не совершения сделки между ним и заказчиком, иногда имеется в виду, что речь должна идти только о таких действиях риэлтора, которые направлены на заключение и исполнение им договора поручения.

При этом создается противоречивая ситуация; получается, что в предмет договора на оказание риэлторских услуг, в содержание этой услуги включаются действия по заключению самого договора на оказание риэлторских услуг.

Если при таком содержании договора с риэлтором, например, между сторонами возникнет спор, который станет предметом судебного рассмотрения, то суд вряд ли согласится с включением в такой гражданско-правовой договор в качестве оплачиваемой риэлтору услуги его действия по заключению самого договора поручения между ним и доверителем.

Также распространенным является мнение о возможности заключения между риэлтором и его клиентом договора комиссии. Такая позиция была даже нормативно закреплена в определении риэлторской деятельности, содержавшимся в утратившем силу в настоящее время постановлении Правительства Российской Федерации. 
С учетом налоговых и иных правовых последствий сделок с недвижимостью, например, в виде перехода права собственности на объект недвижимости на комиссионера (риэлторскую организацию) и необходимости еще одного договора купли-продажи для перехода данного права на покупателя (заказчика риэлторских услуг), представляется экономически нецелесообразным, а практически невозможным использование договора комиссии с участием риэлторской организации в сделках с недвижимым имуществом.

3. К объединенным или совмещенным услугам риэлторов фактического и одновременно юридического (юридико-фактического) характера следует отнести только такие действия или деятельность риэлтора, которые направлены как на формирование воли участников на заключение сделки, так и, в то же время, на изъявление воли участников сделки и надлежащее оформление их волеизъявления.

К таким услугам следует отнести только такие действия или деятельность риэлтора, которые он совершает, например, в процессе заключения и исполнения договора доверительное управление недвижимым имуществом.

Часто к третьей группе риэлторских услуг относят договор агентирования, предмет которого может включать в себя действия или деятельность риэлтора как фактического, так и юридического характера, что вызывает некоторые сомнения.

Действительно, предмет договора агентирования, по сути, включает в себя (объединяет) предметы обоих гражданско-правовых договоров: поручения и комиссии.

При этом допустимость фактического использования в сделках с объектами недвижимого имущества части предмета договора агентирования, тождественной предмету договора поручения, не вызывает никаких возражений.

Сложнее дело обстоит с допустимостью включения в содержание договора по поводу объекта недвижимого имущества той части предмета договора агентирования, которая составляет набор действий риэлтора, тождественных услугам, предоставляемым по договору комиссии.

Также возникает вопрос о практической невозможности использования риэлторской организацией договора агентирования в тех случаях, когда агент не является представителем своего заказчика, а только действует в интересах заказчика, но от своего имени.

Нам представляется более правильным отрицательный ответ на этот вопрос. Здесь также применима аргументация, аналогичная той, которая приведена нами выше при отрицании возможности использования договора комиссии как основания участия риэлтора в качестве стороны сделки с недвижимым имуществом.

При анализе соотношения посреднических и юридических услуг необходимо учитывать несовпадение его результатов с классификацией риэлторских услуг на фактические и юридические услуги.

Так, интересным, но не исчерпывающим всего разнообразия риэлторских услуг, представляется выделение и сравнение следующих услуг:

1) посреднические услуги, которые могут, но чаще всего не включают в себя юридические услуги;

2) иные услуги риэлторской организации, не имеющие посреднического характера (информационные, консультационные и др.), в том числе юридические услуги.

Представляется правильным вывод о том, что юридические услуги могут оказываться заказчику в процессе как посреднической, так и иной деятельности риэлторской организации.

\section{Библиографический список}

1. Саттарова Н.А., Шохин С. О. Отдельные вопросы государственного администрирования в сфере обеспечения финансовой безопасности // Вестник Пермского университета. Юридические науки. 2018. Вып. 40. С. 167-185. DOI: 10.17072/1995-4190-2018-40-167-185

2. Шаипова С.А., Тремаскин И.Э. Налоговая привлекательность государства на примере налога на прибыль организаций в Российской Федерации и Китайской народной республике // Вопросы экономики и права. 2019. № 131. С. 36-39. DOI: 10.14451/2.131.36

3. См.: Кот М.К., Белозерова О.А., Шпанагель Ф. Ф. Преимущества и риски цифровой экономики: правовой и экономический аспекты // Актуальные проблемы правоведения. 2018. № 4 (60). С. 6-11. 
4. Шаблова Е.Г. Гражданско-правовое регулирование отношений возмездного оказания услуг: дисс. ... д-ра юрид. наук. Екатеринбург. 2003. 363 с. [Электронный ресурс]. Режим доступа: lawlibrary.ru disser2015499. html (Дата обращения: 20.04.2020).

5. Гражданский кодекс Российской Федерации. Часть первая. [Электронный документ]. Режим доступа: http:// base.garant.ru/3960835/\#block_11\#ixzz4HOxRНc99// (Дата обращения: 20.04.2020).

6. Петелин Д.В. Договорное регулирование риэлторской деятельности в Российской Федерации: дисс. ... канд. юрид. наук. Москва. 2008. 220 с. [Электронный ресурс]. Режим доступа: lawlibrary.ru>izdanie2077169. html (Дата доступа: 20.04.2020).

7. Подробнее о функциях, природе и различных аспектах посредничества см.: Фастова М.А., Иванова Т. М. Теоретико-правовые аспекты посредничества с позиции функциональной теории // Вопросы экономики и права. 2019. № 131. С. 36-39. DOI: 10.14451/2.133.22 ISSN: 2072-5574

8. См. пункт 2 Положения о лицензировании риэлторской деятельности, утвержденного постановлением Правительства Российской Федерации от 23 ноября 1996 г. N 1407 [Электронный документ]. // Режим доступа: http://base.garant.ru/3960835/\#block_11\#ixzz4HOxRНc99// (Дата доступа: 20.04.2020). 